\title{
Una mirada rápida al control de calidad interno en el quehacer diario del laboratorio de microbiología
}

\author{
A quick look at internal quality control in the daily \\ routine of the microbiology laboratory
}

\section{Gloria I. Morales-Parra MSc', Glorismar Castro-Amaris Microbiol', Yulieth C. Mendoza-Bolaño Microbiol', Luis A. Rubiano-Orozco Microbiol'2, Janeth M. Pacheco-Villa Microbiol²}

Resumen: el laboratorio de microbiología es un sistema complejo que implica muchos pasos para cada actividad, requiere de diversas personas y cuyos resultados analíticos generados deben ser lo más exactos posible. De no ser así, las consecuencias se pueden volver muy significativas, entre ellas, la realización de procedimientos innecesarios al paciente, los retrasos en la obtención de un resultado correcto y la ejecución de pruebas diagnósticas adicionales que se podían evitar. Estas consecuencias incrementan los gastos, tanto en términos económicos como en tiempo y esfuerzos del personal. La mayoría de las técnicas analíticas implican diversos procedimientos que están sujetos a cierto grado de imprecisión y posibilidad de error. Por tal razón, es importante la realización de un control de calidad interno que asegure que los productos finales o valores analíticos, que son producidos por un laboratorio, sean lo suficientemente fiables y adecuados para la finalidad que persiguen. De esta manera, un laboratorio microbiológico debe evaluar y documentar el desempeño de todos los aspectos de sus procedimientos, que incluye la calidad de la muestra, la eficiencia de los reactivos y antisueros, las coloraciones, los medios de cultivo, el funcionamiento de instrumentos o equipos, las cepas de referencia y la verificación o validación de los resultados obtenidos. El objetivo de este manuscrito es presentar una revisión bibliográfica sobre algunos elementos del laboratorio de microbiología susceptibles de control de calidad interno, como parte integral del trabajo diario del personal que labora en este.

Palabras clave: control de calidad, medios de cultivo, coloración y etiquetado, reactivos, equipos.

Morales-Parra GI, Castro-Amaris G, Mendoza-Bolaño YC, Rubiano-Orozco LA, Pacheco-Villa JM. Una mirada rápida al control de calidad interno en el quehacer diario del laboratorio de microbiología. Medicina \& Laboratorio 2017; 23: 459-474.

${ }^{1}$ Bacterióloga y Laboratorista Clínico, especialista en Microbiología Médica, MSc en Microbiología Molecular. Docente investigador, Universidad Popular del Cesar (UPC). Valledupar, Colombia. Correo electrónico: gloriaudes7@hotmail.com ${ }^{2}$ Estudiantes programa de Microbiología, Universidad Popular del Cesar (UPC). Valledupar, Colombia.

\footnotetext{
Conflicto de intereses: Ios autores declaran que no tienen conflictos de intereses Medicina \& Laboratorio 2017; 23: 459-474

Módulo 24 (Administración), número 17. Editora Médica Colombiana S. A. $2017^{\circ}$ Recibido el 04 de septiembre de 2017; aceptado el 16 de octubre de 2017
} 
$\mathbf{E}$ la actualidad, los laboratorios de microbiología han ganado un lugar importante en todos los campos de la ciencia. Las investigaciones microbiológicas son importantes para el diagnóstico, el tratamiento y la vigilancia de las enfermedades infecciosas y para el establecimiento de políticas relacionadas con la selección y el uso de medicamentos antimicrobianos [1]. En la práctica de la bacteriología clínica se procesan múltiples muestras que necesitan indicaciones y requisitos mínimos para su procesamiento. Además, se requiere de operadores capacitados, ya que algunos procesos son difíciles de automatizar $y$, tanto en la fase analítica como en la posanalítica, existen problemas de interpretación de los resultados a causa de la presencia de contaminantes o colonización con la microbiota normal, de los reportes, como los resultados preliminares de la tinción de Gram y cultivos en progreso, y en la aplicación e interpretación de reglas de sistemas [2]. Por lo tanto, el área de microbiología se considera menos susceptible a los Sistemas de Gestión de la Calidad (QMS, por sus siglas en inglés) que otras disciplinas del laboratorio, que tienen objetivos únicos y generan resultados cuantitativos automáticos que permiten el monitoreo estadístico y la calidad de los resultados [3].

Los laboratorios de microbiología, en su actividad diaria para el proceso de identificación bacteriana, deben elaborar y realizar un proceso normalizado que utilice, de forma secuencial, o simultánea, un conjunto de pruebas cuyo propósito final sea la tipificación del microorganismo y que incluyan la mayoría de las bacterias de importancia desde el punto de vista infeccioso [4]. Para esto se deben monitorear, de forma permanente, los instrumentos y los equipos, los medios de cultivo, los reactivos, las co- loraciones y las pruebas de susceptibilidad antimicrobiana empleados, al igual que el personal involucrado en la generación de la información de utilidad clínica, para garantizar un resultado $100 \%$ confiable.

La calidad de un laboratorio implica la aplicación de parámetros relacionados con la exactitud, la fiabilidad y la puntualidad en la entrega de los resultados analíticos obtenidos. Si los resultados son inexactos, las consecuencias pueden ser muy significativas, entre ellas la aplicación de tratamientos innecesarios, inadecuados y sus posibles complicaciones, los retrasos en la obtención de un diagnóstico correcto y la realización de pruebas diagnósticas adicionales [5].

El control de calidad se define como el conjunto de técnicas y actividades operacionales para comparar los resultados obtenidos con los requisitos especificados previamente. El control de calidad interno permite detectar errores aleatorios y sistemáticos mediante la inclusión de muestras de control de calidad en los ensayos realizados en el laboratorio, en el monitoreo de equipos y en los procesos de auditoría [6]. Sin el control de calidad los laboratorios clínicos no podrían mantener un grado de eficiencia, reproducibilidad y confianza de los resultados, de tal forma que contribuyan al diagnóstico y tratamiento de las diversas enfermedades que padece el paciente [7].

Así, cuando se detecte algún resultado anómalo, habrá que investigar cuál ha sido la causa, mediante un análisis retrospectivo del ensayo y, una vez determinada, llevar a cabo las acciones correctivas para eliminar la fuente de error y las acciones preventivas para que no vuelva a ocurrir. Todos los procedimientos y técnicas de control de calidad que se ejecuten deben quedar registrados 
de manera detallada, donde se indique la persona que las ha llevado a cabo, incluso si se ha detectado alguna incidencia y las acciones correctivas realizadas [8]. El objetivo de este manuscrito es presentar una revisión bibliográfica sobre los elementos importantes en los procesos de control de calidad interno, como parte integral del trabajo diario del personal que trabaja en el laboratorio de microbiología.

\section{Validación y verificación de métodos microbiológicos}

Tanto los métodos de ensayo como los laboratorios que realizan los análisis deben asegurar al máximo la fiabilidad de los resultados. Esto implica que, además de reunir los criterios técnicos que aseguren su validez, deben ser realizados con una serie de garantías que permitan obtener resultados comparables, independientemente del laboratorio que los ejecute. En este sentido, el empleo de métodos de referencia, reconocidos y aceptados, es la herramienta más eficaz para obtener estas garantías [9].

Es necesario, entonces, que se implemente la evaluación y validación de métodos y resultados. La evaluación es un proceso sistemático y amplio en el que se comparan diferentes sistemas concebidos para cumplir la misma función o funciones similares. Las evaluaciones en el campo de la microbiología incluyen la comparación de distintos métodos diseñados para detectar el mismo marcador o diana, la comparación de diferentes medios de cultivo para aislar el mismo organismo o la comparación de distintos instrumentos con la misma función. En la validación se aporta la documentación que indique que una prueba diagnóstica o un aparato están funcionando de acuerdo con las especificaciones del fabricante [10].

Dado que en el campo microbiológico se producen situaciones diferenciadoras importantes, respecto de otros campos, como las mutaciones de algunos microorganismos, el uso de métodos que no son definitivos y el hecho de que diferentes microorganismos pueden actuar de la misma manera en cuanto a los resultados fenotípicos obtenidos en el crecimiento in vitro, o mediante una prueba bioquímica determinada, es necesario comprobar y verificar la validez de los procedimientos y resultados a través del uso de cepas de referencia de microorganismos suministrados por una colección nacional o internacional reconocida $[9,11]$, al igual que el control de calidad de la muestra clínica y el monitoreo de los reactivos, las coloraciones, los medios de cultivo, las pruebas, los instrumentos y los equipos usados para la identificación microbiológica [12], como se describirá a continuación.

\section{Calidad de la muestra clínica}

Toda la información diagnóstica que el laboratorio de microbiología puede proporcionar depende de la calidad de la muestra recibida. Una toma de la muestra mal realizada, pobremente recogida o mal transportada, determinará un posible fallo en la recuperación de los agentes patógenos, lo que puede inducir a errores diagnósticos e incluso a un tratamiento inadecuado del enfermo [13]. Si el laboratorio no recibe una muestra apropiada no puede dar un informe de utilidad clínica y, en muchos casos, puede confundir y alejar al clínico del verdadero agente etiológico de la enfermedad, lo que da lugar a pérdidas económicas, mala 
utilización de recursos por aumento en los costos hospitalarios y del laboratorio, impacto en el tratamiento y control de las infecciones, duración de la hospitalización y, lo más grave, a errores diagnósticos de gran impacto en el pronóstico y la seguridad en la atención de los pacientes [14,15].

Debido a que la interpretación de los resultados en microbiología depende completamente de la calidad de la muestra enviada para el análisis, el manejo de la muestra no se puede dejar al azar y se debe asegurar que llegue al laboratorio lo más rápido posible después de su recolección, ya que los microorganismos pueden crecer, multiplicarse o morir rápidamente cuando existe una indebida recolección, transporte y conservación [16].

Para asegurar el diagnóstico correcto del patógeno existen normas básicas para la recolección correcta de las muestras biológicas. Las muestras se deben obtener en el periodo donde haya mayor excreción del agente infeccioso y del sitio representativo de la infección, en cantidad suficiente, sin que se contaminen con tejidos, secreciones adyacentes o microbiota normal, por lo que se deben utilizar las máximas condiciones de asepsia [13,17-19]. En la tabla 1 se listan algunos sitios de infección y las posibles fuentes de contaminación con microbiota saprófita, que se deben tener en cuenta para una adecuada toma de la muestra.

También se deben establecer los periodos óptimos para recolectar la muestra, de acuerdo con el proceso natural de la enfermedad y del microorganismo involucrado; esto para aumentar las posibilidades de recuperar el agente etiológico. Además, se deben utilizar recipientes de recolección y medios de transporte adecuados para asegurar el aislamiento de los microorganismos. En lo
Tabla 1. Sitios de infección y sus posibles fuentes de contaminación con microbiota saprófita

\begin{tabular}{ll}
\hline Sitio de infección & Fuente de contaminación \\
\hline Vejiga & Uretra y perineo \\
$\begin{array}{l}\text { Sangre } \\
\text { Cuello uterino y } \\
\text { endometrio }\end{array}$ & Sitio de punción \\
\hline $\begin{array}{l}\text { Fístula } \\
\text { Oído medio }\end{array}$ & Tracto gastrointestinal \\
\hline $\begin{array}{l}\text { Cornetes nasales } \\
\text { Infecciones subcu- }\end{array}$ & Microbiota del conducto \\
táneas y heridas & Piel y mucosas \\
superficiales & \\
\hline $\begin{array}{l}\text { Tracto respiratorio } \\
\text { superior }\end{array}$ & Cavidad oral y nasofaringe \\
\hline $\begin{array}{l}\text { Tomado de Manual práctico de bacteriología clínica (p.12) } \\
\text { por J. Velasco y colaboradores, 2008, Mérida, Venezuela: } \\
\text { Publicaciones Vicerrectorado Académico, CODEPRE. Co- } \\
\text { pyright@ 2008 por Universidad de Los Andes Vicerrectorado } \\
\text { Académico, CODEPRE y los autores [18]. }\end{array}$ \\
\hline
\end{tabular}

posible, la muestra se debe obtener antes de instaurar una terapia antimicrobiana, o antes de introducir cualquier modificación en esta, debido a que se disminuye la posibilidad de recuperar el agente infeccioso implicado. Cuando la viabilidad de los microorganismos es muy escasa, o la posibilidad de desecación de la muestra es grande (lo que favorece la destrucción bacteriana) y la toma de la muestra no se puede realizar en el mismo laboratorio de procesamiento, se deben usar medios de transporte específicos (p. ej. Cary Blair, Stuart o Amies), que tienen un $\mathrm{pH}$ regulado y agentes reductores para la recuperación de bacterias anaerobias y la viabilidad de la mayoría de los patógenos [13,17-19].

Es indispensable, entonces, que todo laboratorio de microbiología tenga un manual de toma, recolección y manipulación de la muestra clínica, actualizado con base en las últimas evidencias disponibles y en el que 
se detalle: tipo de muestra apropiado para cada caso, forma de recolección de la muestra, condiciones de transporte hacia el laboratorio (tiempo de transporte ideal, tipo de envase para la recolección de la muestra y temperatura de transporte) y conservación de la muestra $[16,17,20]$.

\section{Reactivos de identificación}

Un elemento fundamental en el trabajo diario de laboratorio lo constituyen los reactivos, tanto comerciales como de preparación doméstica, que son utilizados para la caracterización de los microorganismos. Estos reactivos merecen una especial atención, ya que fallas en su funcionamiento pueden generar identificaciones equivocadas. Por ello, se recomienda realizar controles diarios, o cada vez que se use el reactivo, con las cepas de bacterias adecuadas, y seguir estrictamente las indicaciones en cuanto al almacenamiento, la metodología de uso y el tiempo de lectura [21].

Se consideran como reactivos del laboratorio de microbiología, entre otros, los discos con reactivos o con antimicrobianos, los reactivos preparados internamente y los estuches o sistemas comerciales que incorporan una variedad de medios, sustancias bioquímicas y reactivos, o cualquier combinación de estos. Es indispensable que todos los reactivos (incluidas las soluciones stock o de reserva), diluyentes y otros líquidos de suspensión estén bien preparados y que tengan un funcionamiento óptimo para garantizar unos resultados confiables [22].

Para cada reactivo debe existir una ficha técnica de elaboración, que incluya el control de esterilidad y de funcionamiento adecuado, al igual que un registro en el que se indique la fecha de preparación, la validación realizada y las personas responsables. Todos los reactivos deben estar etiquetados con sus componentes, la indicación (ensayo microbiológico para el que se utiliza), la concentración, las condiciones de conservación, la fecha de preparación o de reconstitución y la fecha de caducidad o periodo recomendado de almacenamiento, los controles que se deben utilizar y los criterios de aceptabilidad, el plan y la frecuencia de control, las limitaciones de su uso o de interpretación, la descripción del tipo de lectura de los resultados y el método de lectura. Para el control de todos los reactivos se deben utilizar cepas de referencia, conservadas de acuerdo con las recomendaciones de los fabricantes, e incluir un microorganismo que produzca una reacción positiva y otra negativa por cada control $[8,23]$.

Los estuches comerciales se deben comprar solamente de casas fabricantes renombradas y almacenarlos como lo indican las instrucciones. Estos se deben utilizar según lo recomendado y cualquier modificación al procedimiento se debe considerar como una modificación al método; por lo tanto, requiere de validación estándar. Al abrir un estuche por primera vez se debe comprobar la fecha de caducidad, para asegurar que continúa siendo válido; además, la fecha en la que fue abierto debe ser rotulada en la caja o contenedor. Los estuches comerciales se suministran, generalmente, con los controles que se deben utilizar en cada ocasión. Es recomendable que los reactivos comerciales sean analizados, de forma inmediata, cuando se abre un nuevo lote o vial, y llevar un registro de su funcionamiento [23].

En la tabla 2 se listan algunos reactivos usados en el laboratorio de microbiología y los resultados del control de calidad esperados. 
Tabla 2. Control de calidad de los reactivos usados en el laboratorio de microbiología y reacciones esperadas

\begin{tabular}{lll}
\hline Reactivo & Cepa control & Reacciones esperadas \\
\hline Kovacs (Indol) & Escherichia coli & Positiva: anillo fucsia o rojo \\
Klebsiella pneumoniae & Negativa: anillo amarillo
\end{tabular}

\section{Coloraciones}

Aunque los microorganismos vivos se pueden observar directamente en muestras frescas en el microscopio óptico, la mayoría de las veces es necesario teñirlos con colorantes para que sea más fácil su identificación. Además, la presencia de ciertas estructuras, así como su reacción a determinadas técnicas de coloración, permite clasificar a las bacterias en diferentes grupos y acercarse al diagnóstico microbiológico. El advenimiento de las tinciones, a mediados del siglo XIX fue, en gran parte, responsable de los principales avances que se tuvieron en la microbiología y en otros campos del diagnóstico microscópico durante los últimos cien años. Las coloraciones, y en especial la tinción de Gram, se han convertido en una herramienta básica para el diagnóstico preliminar y presuntivo de los agentes infecciosos, y una valiosa guía de orientación diagnóstica [26].

Las tinciones son frecuentes en el área de microbiología y otras áreas del laboratorio como hematología, análisis de orina, citología, histología y parasitología. En microbiología se utilizan con frecuencia tinciones permanentes, como la naranja de acridina, la hematoxilina férrica (para los parásitos fecales) y la tinción cromosómica de Giemsa (para Plasmodium spp.). La tinción de Gram se utiliza para la identificación de bacterias, levaduras y otros elementos presentes en las muestras clínicas, como células epiteliales y leucocitos polimorfonucleares neutrófilos. Las tinciones acidorresistentes son especialmente importantes para el diagnóstico preliminar de las micobacterias, puesto que su crecimiento tarda varias semanas [5]. 
Cabe anotar que la tinción de Gram es una de las más utilizadas universalmente debido a lo económica, sencilla y eficaz que resulta [27]. Esta tinción, en microbiología clínica, resulta de gran utilidad, ya que a partir de muestras clínicas directas, provenientes de sitios estériles, se puede saber de manera rápida las características de la muestra y hacer una diferencia de los potenciales microorganismos causantes de la infección [28]. Además, esta coloración resulta ser la carta de navegación del microbiólogo, que orienta el diagnóstico del agente infeccioso $y$, en algunos casos, por su alta sensibilidad y especificidad, se convierte en una prueba diagnóstica importante de infecciones como las del tracto urinario en lactantes y recién nacidos [29-31], la vaginosis bacteriana en mujeres [32,33] y la uretritis gonocócica en hombres [34-36]; por lo que es considerada la coloración estándar de referencia en el laboratorio de microbiología.

Las tinciones utilizadas en el laboratorio de microbiología permiten el diagnóstico oportuno y sugerente de los agentes implicados en las enfermedades infecciosas, por lo que pueden ser determinantes en la decisión del tratamiento inicial, lo que las convierte en herramientas elementales, vigentes y de uso universal. Por tal razón, es importante practicar la tinción adecuada de acuerdo con el agente infeccioso que se sospecha y el tipo de muestra a procesar [37].

La concentración de las soluciones de tinción, debido al efecto de la evaporación de los solventes o las variaciones introducidas en los métodos recomendados, puede afectar los resultados de las tinciones para diferenciar los microorganismos, de acuerdo con su reacción a la tinción de Gram y su morfología, y a coloraciones especiales para la tinción de cápsulas, esporas, entre otros.
Específicamente, la tinción de Gram se puede ver afectada en su interpretación ya que, a pesar de su sencillez, existen bacterias de un mismo género que se pueden observar en la misma muestra como Gram positivas y Gram negativas de forma simultánea, evento denominado "tinción Gram variable", lo cual se produce secundario al estrés del crecimiento de la bacteria debido a la alteración en la cantidad de nutrientes, en la temperatura, el pH o la concentración de electrolitos disponibles en el medio de cultivo del que es realizada la coloración, o bien, porque, por ejemplo, algunas especies de Bacillus y Gardnerella vaginalis a menudo se tiñen Gram negativos o Gram variables, a medida que los cultivos envejecen, o debido a la estructura o cambios en la pared celular relacionados con pérdida de la viabilidad $[25,38]$.

Por lo anterior, las tinciones se deben comprobar todos los días de uso con cepas de control de calidad que presenten resultados positivos y negativos para cada tinción, a fin de garantizar que sus reactivos están activos y en buen estado, además, que ofrecen los resultados esperados. Por ejemplo, para el control diario de la tinción de Gram se recomienda el uso de cepas de Staphylococcus aureus y de Escherichia coli del American Type Culture Collection (ATCC) [21].

Todos los resultados de control de calidad se deben registrar siempre que se analicen. Las tinciones también se deben examinar en búsqueda de precipitaciones o formación de cristales, y para comprobar si hay contaminación bacteriana; de ser así, es recomendable la filtración de los tintes. Un mantenimiento y cuidado atento de las existencias y de las diluciones de análisis de las tinciones constituye un componente primordial en un sistema que ofrezca buena calidad en los análisis de microscopía [5]. 


\section{Medios de cultivo}

Desde la época de Robert Koch hasta hoy día se ha incrementado enormemente el arsenal de medios de cultivo con que cuentan los microbiólogos para la identificación microbiana. La expansión de la microbiología a otras áreas ha sido la responsable directa de tal incremento, donde ha pasado de la medicina hacia la agricultura y las industrias de alimentos y farmacéutica. Dado que los medios de cultivo constituyen una herramienta fundamental en los laboratorios de microbiología, realizar pruebas de control de calidad de estos es vital para comprobar si cumplen con sus especificaciones y si la metodología empleada para su preparación es satisfactoria [39].

Es importante tener en cuenta que en el caso de los medios de cultivo deshidratados la calidad depende del ambiente de almacenamiento, especialmente después de abrir un nuevo recipiente. La pérdida de la calidad de estos medios se manifiesta por un cambio en las características de flujo del polvo, pérdida de la homogeneidad, apelmazamiento, cambios de color, entre otros. Todo medio de cultivo deshidratado que haya absorbido humedad o muestre signos manifiestos de cambio en la apariencia física se debe desechar. De esta manera, cada vez que se utilice un medio deshidratado se debe hacer una evaluación visual del contenido para verificar el aspecto, las condiciones físicas y el cumplimiento de los criterios mínimos de rendimiento para obtener un análisis microbiológico fiable [40]. Para los medios que son preparados por el laboratorio de microbiología la evaluación se debe realizar para cada lote que se prepare antes de su uso rutinario; para los medios comerciales se realiza la verificación del rendimiento en cada nuevo número de lote y, cada vez que se abre una nueva serie, se deben verificar sus características con el uso de cepas control específicas, dependiendo del tipo de medio [5,24].

Los procedimientos de control de calidad proporcionan la confianza de que los medios no se han contaminado antes de su uso y que cumplen con las características mínimas para el crecimiento del microorganismo inoculado. En todos los casos, ya sean medios adquiridos o realizados en el centro de análisis microbiológico, se deben comprobar atentamente aspectos como la apariencia, el aspecto, la dureza, la profundidad del agar, el pH, el cumplimiento de las características para el crecimiento microbiano, la capacidad de reacción, entendida como la capacidad para ofrecer los resultados bioquímicos adecuados, la selectividad y su vida útil; esta última se verifica reteniendo suficientes alícuotas de los medios para repetir los controles en la fecha de vencimiento.

Un aspecto muy importante para evaluar es la esterilidad del medio de cultivo después de su preparación, la cual es comprobada mediante la incubación de una alícuota del $5 \%$ de cada lote preparado, a una temperatura de $37{ }^{\circ} \mathrm{C} \pm 1{ }^{\circ} \mathrm{C}$, por un espacio de 24 y 48 horas. En caso de evidenciar contaminación se debe rechazar el lote preparado. Es importante mantener registros minuciosos de los medios que se preparan en el laboratorio. Se debe mantener un registro diario que documente la fecha y el nombre de la persona que realizó la preparación, nombre del medio y del fabricante, números de lote y de serie asignados, el color, la consistencia, la apariencia, los resultados del análisis de crecimiento y el pH $[22,23]$.

El control de calidad interno de los medios de cultivo producidos internamente se debe 


\begin{tabular}{|c|c|c|}
\hline Medios de cultivo & Organismo control & Reacción esperada \\
\hline Agar chocolate & $\begin{array}{l}\text { Haemophilus influenzae } \\
\text { Neisseria gonorrhoeae }\end{array}$ & $\begin{array}{l}\text { Crecimiento } \\
\text { Crecimiento }\end{array}$ \\
\hline Agar sangre & $\begin{array}{l}\text { Streptococcus pneumoniae } \\
\text { Streptococcus agalactiae } \\
\text { Enterococcus spp. }\end{array}$ & $\begin{array}{l}\text { Hemólisis alfa } \\
\text { Hemólisis beta } \\
\text { No produce hemólisis }\end{array}$ \\
\hline Agar MacConkey & $\begin{array}{l}\text { Escherichia coli } \\
\text { Enterococcus faecalis }\end{array}$ & $\begin{array}{l}\text { Colonias rosadas } \\
\text { No crecimiento }\end{array}$ \\
\hline Agar manitol salado & $\begin{array}{l}\text { Staphylococcus aureus } \\
\text { Escherichia coli }\end{array}$ & $\begin{array}{l}\text { Colonias amarillas } \\
\text { No crecimiento }\end{array}$ \\
\hline Citrato Simmons & $\begin{array}{l}\text { Klebsiella pneumoniae } \\
\text { Escherichia coli }\end{array}$ & $\begin{array}{l}\text { Color azul oscuro del medio } \\
\text { No crece/cultivo color verde }\end{array}$ \\
\hline Hektoen & $\begin{array}{l}\text { Escherichia coli } \\
\text { Salmonella spp. } \\
\text { Shigella spp. }\end{array}$ & $\begin{array}{l}\text { Colonias anaranjadas brillantes } \\
\text { Colonias verde azuladas con centros negros } \\
\text { Colonias transparentes sin producción de } \mathrm{H}_{2} \mathrm{~S}\end{array}$ \\
\hline Agar SS & $\begin{array}{l}\text { Escherichia coli } \\
\text { Salmonella spp. }\end{array}$ & $\begin{array}{l}\text { Colonias rosadas } \\
\text { Colonias incoloras con } \mathrm{H}_{2} \mathrm{~S}\end{array}$ \\
\hline Fenilalanina desaminasa & $\begin{array}{l}\text { Proteus spp. } \\
\text { Escherichia coli }\end{array}$ & $\begin{array}{l}\text { Aparición inmediata de color verde intenso } \\
\text { No cambio de color }\end{array}$ \\
\hline \multicolumn{3}{|c|}{$\begin{array}{l}\text { Tomado y modificado de "Control de la Calidad para un Laboratorio de Microbiología" por M.L. Herrera \& M. Campos, 2005, Rev } \\
\text { Méd Hosp Nac Niños, 40, p. 12. Copyright@C } 2005 \text { por Scielo [21]; y Recomendaciones sobre el aseguramiento de la calidad de } \\
\text { medios de cultivo y reactivos (p. 31-34) por C. Miranda y colaboradores. En: Recomendaciones generales para el control de calidad } \\
\text { interno en Microbiología Clínica por Grupo Colaborador GEGMIC (ed), 2004, Madrid, España: SEIMC [41]. }\end{array}$} \\
\hline
\end{tabular}

realizar mediante la inoculación de un microorganismo de control verificado, con comportamiento conocido, tanto para reacciones positivas como para negativas, tipo ATCC y que se haya preservado y subcultivado de acuerdo con las pautas del proveedor [23].

En la tabla 3 se listan algunos medios de cultivo y la reacción esperada al realizar el control de calidad de estos.

\section{Pruebas de susceptibili- dad antimicrobiana}

En los laboratorios de microbiología clínica la identificación microbiana y la determinación de la sensibilidad de los microorganismos a los antibióticos son tareas con un gran impacto en el manejo del paciente infectado. Los métodos utilizados para la de- terminación de la sensibilidad se basan en un estudio fenotípico, en el que se observa el crecimiento de los aislamientos bacterianos en presencia del antibiótico a estudiar. Entre los métodos utilizados para esta evaluación se incluyen el de dilución en agar, la macro y microdilución en caldo, las tiras reactivas con un gradiente de antibiótico ( $\mathrm{E}-$ test) y la difusión en agar (método de KirbyBauer) [42].

Independiente del método utilizado las pruebas de susceptibilidad antimicrobiana se basan en la evaluación in vitro de la capacidad que tienen los antibióticos o los agentes antimicrobianos de inhibir el crecimiento bacteriano. El resultado final de las pruebas de susceptibilidad está influenciado por múltiples factores, lo que hace necesario el monitoreo constante de los procedimientos aplicados en su ejecución mediante 
un programa de control de calidad interno, que considere aspectos como la densidad del inóculo, la temperatura de incubación, la composición de los medios de cultivo preparados o comprados y los contenidos de los discos con antimicrobianos. De esta forma, la precisión y exactitud del método pueden ser controladas mediante el uso de cepas bacterianas de referencia, cuyos patrones de susceptibilidad son conocidos, y la aplicación de un procedimiento estandarizado que incluya todas las etapas de la ejecución del antibiograma tal como se realiza en la rutina [43].

El inóculo bacteriano es una parte fundamental en las pruebas de sensibilidad antimicrobiana; por esta razón, se recomienda el uso de un inóculo estandarizado con una turbidez al 0,5 de la escala de McFarland. Este estándar de turbidez se debe conservar a temperatura ambiente y en oscuridad. En cuanto al control de calidad del medio de cultivo es recomendable el uso del agar Müller-Hinton, el cual es altamente reproducible para los ensayos de susceptibilidad antimicrobiana, tiene bajo contenido de inhibidores que afectan las tetraciclinas, las sulfonamidas y la trimetoprima/sulfametoxazol y permite el crecimiento de microorganismos no fastidiosos. Entre las características mínimas que debe tener este agar están una profundidad de $4 \mathrm{~mm}$ y un pH entre 7,2 y 7,4 [44].

La cantidad de cationes divalentes, principalmente del calcio y el magnesio, en el agar Müller-Hinton es otra variable que se debe controlar, ya que puede afectar los resultados con los aminoglucósidos, las tetraciclinas y la colistina. Cuando se encuentran en exceso reducen la zona de inhibición de estos agentes, mientras que si su contenido es escaso pueden inducir un aumento in- aceptable en el tamaño de dicha zona. Por otra parte, la cantidad de timina y timidina también se debe tener en cuenta pues puede alterar los resultados de las sulfonamidas y la trimetoprima, al producir una falsa sensibilidad o una falsa resistencia [44]. De esta manera, para controlar las concentraciones de timina/timidina se utiliza la cepa de Enterococcus faecalis ATCC 29212 y el disco de trimetoprima/sulfametoxazol, y para las concentraciones de cationes la cepa de Pseudomonas aeruginosa ATCC 27853 y el disco de gentamicina $[21,45]$.

El Instituto de Estándares Clínicos y de Laboratorio (CLSI, por sus siglas en inglés) recomienda el uso de cepas ATCC de referencia y genéticamente estables para el control de calidad de las pruebas de susceptibilidad antimicrobiana, de manera que se pueda garantizar que el sistema de prueba está funcionando de forma adecuada, específicamente en lo que respecta a la viabilidad del inóculo y el funcionamiento de los antimicrobianos. Cabe anotar que los diámetros de los halos de inhibición, para definir una bacteria como sensible o resistente, determinados por el CLSI para el control de calidad, son válidos solo cuando se realiza el método de susceptibilidad correspondiente al método estándar de referencia del CLSI, o alguno que haya demostrado un desempeño comparable a este [45].

Las cepas ATCC básicas recomendadas por el CLSI para el método de difusión son Escherichia coli ATCC 25922, Staphylococcus aureus ATCC 25923, Pseudomonas aeruginosa ATCC 27853 y Enterococcus faecalis ATCC 29121, entre otras, las cuales se seleccionan de acuerdo con el grupo de antimicrobiano a evaluar y el aislado clínico que vaya a ser sometido a prueba de susceptibilidad. Cabe anotar que el control de calidad para cada 
antimicrobiano se debe realizar de manera diaria o cada vez que el laboratorio realice la prueba de susceptibilidad hasta obtener 20 lecturas; si estas lecturas son correctas (dentro del rango de lectura esperado) se puede pasar a una frecuencia semanal [45].

\section{Equipos de análisis microbiológico}

La calidad de un análisis microbiológico depende, entre otros factores, del buen uso y funcionamiento de los equipos utilizados para este fin. Es fundamental que todos los equipos que resulten críticos para los ensayos de microbiología dispongan de un plan de actividades de mantenimiento, verificación y calibración. Estas actividades están encaminadas a asegurar que los posibles errores detectados en los equipos sean subsanados, así como que el error asociado a los equipos sea asumido por el laboratorio (por ejemplo, la calibración de la estufa, el termociclador, la verificación y la calibración de balanzas, entre otros ) [9].

El laboratorio debe contar con los equipos necesarios para la correcta ejecución de los ensayos y disponer de un inventario actualizado de los equipos en uso. Cuando se recibe un equipo nuevo se debe comprobar que cumple con las especificaciones previstas; además, verificar la documentación que lo acompañe y su estado [46]. La documentación necesaria para cada equipo debe incluir: a) ficha del equipo con la descripción y el código interno asignado al mismo, el nombre, la marca, el modelo, el número de serie, el número de inventario de la institución, la localización habitual, los datos del fabricante, la fecha de recepción y de puesta en servicio, el procedimiento de validación, verificación y mantenimiento, y su periodicidad; además de las precauciones de bioseguridad, b) un manual del equipo, que junto con las instrucciones de uso y mantenimiento deben estar disponibles para el personal del laboratorio autorizado, c) registros de cada una de las revisiones realizadas: mantenimiento preventivo y correctivo, periodicidad de la inspección y fallas del instrumento; además, se debe incluir un apartado de corrección de fallas y acciones correctivas efectuadas $y \mathrm{~d}$ ) instrucciones de uso del instrumento, redactadas en forma clara y en el idioma de los usuarios, en las que se incluyan las precauciones de seguridad, los procedimientos de limpieza, cuidado del instrumento y acciones correctivas $[46,47]$.

La norma UNE-EN-ISO 15189:2007 exige que el laboratorio disponga de un programa de validación, verificación y mantenimiento para los equipos que puedan influir significativamente en los resultados de los ensayos [48]. Después de la validación inicial, los periodos de validación o verificación (comprobación en el día a día de que un equipo cumple con sus especificaciones) se establecen en función de la naturaleza del equipo, sus condiciones de uso, la historia previa del equipo y las recomendaciones del fabricante [49]. El mantenimiento permite que un equipo esté en condiciones de uso adecuadas y puede ser de tipo correctivo o preventivo. El mantenimiento en los equipos, como baños termostáticos, estufas, refrigeradores, cabinas de seguridad biológica y microscopios, consiste en la limpieza, la inspección de posibles daños y la comprobación general. Se deben establecer y conservar los registros del mantenimiento efectuado en los que conste la actividad realizada, cuándo y quién la ha efectuado [50]. 


\section{Cepas de referencia}

Para demostrar la trazabilidad el laboratorio debe utilizar cultivos de referencia de microorganismos obtenidos de una colección nacional o internacional reconocida, o de una organización aprobada por un organismo de acreditación. Teniendo en cuenta que cada aislamiento microbiano es, con una alta probabilidad, distinto de otro aislamiento de la misma especie, cuando se quiere realizar cualquier trabajo microbiológico en condiciones estándar, reproducibles en cualquier momento y lugar, es necesario efectuar el control de calidad con cepas de referencia reconocidas, siendo las más importantes las brindadas por el American Type Culture Collection (ATCC) de Estados Unidos [9].

El laboratorio debe elaborar un procedimiento interno en el que se describan las etapas de reconstitución de las cepas, el medio a utilizar, la producción de cepas de reserva y de trabajo, las pruebas bioquímicas a aplicar, concretando cuáles y cuándo, y el modo y el tiempo de almacenamiento de todos los tipos de cepas (reserva y trabajo). Las tres fases de producción de las cepas (reconstitución, reserva y trabajo) deben estar codificadas y registradas de manera que haya trazabilidad de las cepas de trabajo a la original [9].

Las cepas de referencia recomendadas en microbiología varían según las exigencias de las pruebas analíticas a realizar. De esta forma, para los estudios de sensibilidad se recomiendan las cepas ATCC, o las equivalentes de otras colecciones como las propuestas por el CLSI. Para el resto de pruebas se pueden utilizar las cepas ATCC recomendadas por otros estamentos, o bien, aislados clínicos correctamente caracterizados.
Debe existir un registro documentable de la recepción de las cepas de referencia, en el que se anote la fecha de llegada, condiciones de llegada, controles realizados, método de conservación y número de viales y personal responsable. Las cepas de referencia se deben reconstituir y someter a los controles de pureza y ensayos bioquímicos que sean necesarios; además, ser cultivadas en los medios apropiados una única vez para obtener las cepas de reserva y las cepas de trabajo. Las cepas de reserva se deben conservar mediante una técnica que mantenga las características deseadas de las cepas de referencia, como la liofilización, la ultracongelación $\left(-70^{\circ} \mathrm{C}\right)$, la conservación en nitrógeno líquido, entre otras [41].

\section{Aseguramiento de la calidad}

El laboratorio de microbiología clínica requiere, para su correcto funcionamiento, un adecuado y constante control de calidad de todas las etapas del procesamiento de las muestras clínicas, desde la recolección hasta la elaboración del informe escrito. El aseguramiento de la calidad dentro del laboratorio de análisis clínico tiene como finalidad identificar, monitorear, evaluar y aprobar metodologías relativas al cuidado del paciente, para garantizar un resultado verídico y confiable. En este contexto, el control de calidad en microbiología comprende el monitoreo de los medios de cultivo, reactivos, instrumentos y procedimientos, como ya fue descrito previamente en esta revisión; además del personal involucrado en la generación de la información de utilidad clíni$\mathrm{ca}$, de manera que resulte confiable [12].

Un programa de aseguramiento de la calidad también debe incluir un manual de 
procedimientos para la validación de metodologías y equipos, el desarrollo de cursos de educación continua, elementos de bioseguridad y una supervisión de los reportes generados [21]. De igual manera, para garantizar una adecuada atención médica a los pacientes con patologías infecciosas se deben implementar medidas de control de calidad interno y externo por parte de los laboratorios, las cuales deben abarcar todas las fases del proceso analítico, ya que gracias a ellas se detectan errores sistemáticos o aleatorios, con la consiguiente posibilidad de introducir, si procede, las medidas correctivas adecuadas [51].

\section{Control de calidad interno}

Para finalizar, el control de calidad interno es una parte importante del laboratorio que se puede lograr a través de intervenciones debidamente documentadas y validadas en las etapas preanalítica, analítica y posanalítica. La implementación del control de calidad interno no garantiza un trabajo libre de errores, pero detecta y controla la aparición de los mismos [52]. El programa de control de calidad interno se debe reflejar en un documento donde queden consignados, de manera detallada, todos los procedimientos y técnicas que se lleven a cabo, los resultados correspondientes y la persona que las ha elaborado; en caso de que se detecte alguna incidencia también debe quedar registrada, así como las posibles acciones correctivas realizadas. Cuando se manifieste algún resultado anómalo es necesario investigar cuál ha sido la causa, mediante un examen retrospectivo del ensayo $y$, una vez determinada, realizar las acciones correctivas pertinentes para eliminar la fuente de error, así como las acciones preventivas para que no vuelva a ocurrir [8].

En este sentido, el Instituto Nacional de Salud de Colombia, con base en la norma ISO/ IEC 17025, que plantea programas de aseguramiento de la calidad de los laboratorios para generar resultados técnicamente válidos, plantea al aseguramiento de la calidad (quality assurance) como el conjunto de actividades planificadas y sistemáticas para asegurar que los productos o servicios sean satisfechos [53]. Entre estas actividades se encuentran la medición sistemática de los procesos, la comparación con estándares, el seguimiento de los procesos, entre otras. Estas actividades contribuyen a la prevención de los errores y que los datos del control de la calidad sean analizados; en caso de no satisfacer los criterios predefinidos se deben aplicar las acciones planificadas para corregir el problema y evitar consignar resultados incorrectos [54].

\section{Evaluación externa de la calidad}

Para terminar, la evaluación externa de la calidad se define como un sistema para comprobar, de forma objetiva, el rendimiento del laboratorio por medio de una agencia o instalación externa. Los laboratorios individuales pueden utilizar la evaluación externa de la calidad para detectar problemas en las prácticas del laboratorio, lo que permite la aplicación de las medidas correctivas pertinentes. La participación en la evaluación externa de la calidad ayudará a evaluar la fiabilidad de los métodos, materiales y equipos, y a evaluar y supervisar la influencia de la formación del personal involucrado [5]. 
En los laboratorios que realicen análisis relacionados con la salud pública la evaluación externa de la calidad puede ayudar a garantizar que, durante las actividades de supervisión, los resultados procedentes de diferentes laboratorios sean comparables. La participación en el programa de evaluación externa de la calidad proporciona datos e información útiles para la comparación del rendimiento, y los resultados entre diferentes centros de análisis emiten advertencias tempranas de los problemas sistemáticos asociados a estuches de reactivos $u$ operaciones, proporcionan pruebas objetivas de la calidad de los análisis, indican las zonas que necesitan mejorar e identifican las necesidades de formación del personal del laboratorio. Por lo tanto, la evaluación externa de la calidad ayuda a clientes como médicos, pacientes y autoridades sanitarias para asegurar que el laboratorio produzca resultados fiables [5].

\section{Conclusiones}

El programa de control de calidad, para los análisis cualitativos y cuantitativos, es esencial para garantizar la exactitud y la fiabilidad de las pruebas realizadas por el laboratorio clínico. Por lo tanto, el laboratorio debe establecer un programa que supervise todos los análisis de control de calidad y tener políticas y procedimientos, por escrito, que debe seguir todo el personal del laboratorio.

El programa de control de calidad interno en el laboratorio de microbiología asegura que la información es exacta, adecuada y reproducible, y permite alertar a los profesionales del laboratorio sobre posibles resultados insatisfactorios que pueden y deben ser corregidos. De igual manera, cada laboratorio debe participar en programas de control de calidad externo organizados por organismos oficiales o comunidades científicas, y debe documentar los procedimientos utilizados para la evaluación de los resultados obtenidos y la adopción de medidas correctivas.

Mediante el uso de prácticas de control de calidad un laboratorio es capaz de encontrar y corregir fallas en los procesos analíticos de un laboratorio, antes de que los resultados del paciente sean entregados potencialmente incorrectos, garantizado así la calidad de los reportes, la seguridad de los pacientes y la confiabilidad que el clínico deposita en el laboratorio.

\section{Bibliografía}

1. Arora DR. Quality assurance in microbiology. Indian J Med Microbiol 2004; 22: 81-86.

2. Wilson ML. Assuring the Quality of Clinical Microbiology Test Results. Clin Infect Dis 2008; 47: 1077-1082.

3. Barbe B, Yansouni CP, Affolabi D, Jacobs J. Implementation of quality management for clinical bacteriology in low-resource settings. Clin Microbiol Infect 2017; 23: 426-433.

4. Bou G, Fernández-Olmos A, García C, Sáez-Nieto J-A Valdezate S. Métodos de identificación bacteriana en el laboratorio de microbiología. Enferm Infec Micr Cl 2011; 29: 601-608.

5. Organización Mundial de la Salud (OMS), Centros para el Control y Prevención de Enfermedades (CDC), Instituto de Normas Clínicas y de Laboratorio (CLSI). Sistema de gestión de la calidad en el laboratorio (LQMS)-Manual. Ginebra, Suiza: Organización Mundial de la Salud; 2016.

6. Orta Mira N, Guna Serrano MR, Gimeno Cardona C, Perez JL. [Quality control in molecular microbiology]. Enferm Infecc Microbiol Clin 2008; 26 Suppl 9: 2-7.

7. Sierra-Amor RI. El laboratorio clínico y el control de calidad. Bioquimia 2006; 31: 39-40.

8. Aguiar JM, Cercenado ME, Ory M F, Rojo MD, De La Rosa Fraile M. Recomendaciones para la implantación de la normativa de calidad ISO 15189 en el Laboratorio de Microbiología Clínica: bacteriología y serología. Enferm Infecc Microbiol Clin 2009; 28: 453-460.

9. Camaró-Sala ML, Catalá-Cuenca V, Gimeno-Cardona C, Martínez-García R, Olmos-Martínez P. Validación y verificación analítica de los métodos microbiológicos. In: Cercenado E, Cantón R eds. Procedimientos en Microbiología Clínica: Recomendaciones de la Sociedad Española de Enfermedades Infecciosas y Microbiología Clínica. Madrid, España: Seimc; 2013. 
10. Organización Panamericana de la Salud, Organización Mundial de la Salud, Oficina Regional para Las Americas. Diagnóstico de laboratorio de las infecciones de transmisión sexual, incluida la infección por el virus de la inmunodeficiencia humana. Ginebra, Suiza: Organización Mundial de la Salud; 2014.

11. Robert Pullés M, Mayarí Navarro R, Martínez Morales V. Criterios para la acreditación de laboratorios que realizan ensayos microbiológicos según NC-ISO/IEC 17025:00. Revista CENIC 2006; 37: 32-36.

12. Zárate MS, Dadamio J, Alí S, Giordanelli A, Smayevsky J, Torres M. Desarrollo y evaluación de una muestra para control de calidad en Microbiología. Acta bioquím Clín Latinoam 2007; 41: 57-61.

13. Crespo-Sánchez MD, Escribano-Garaizábal E, LorenteOrtuño S, Marín-Ors A, Palomar-Pérez JJ, Robles-Dominguez $\mathbf{P}$, et al. Recogida, transporte y conservación de muestras. 2016. Servicio de Microbiología, Complejo Hospitalario, Universitario de Albacete. Disponible: http://www.chospab.es/area_medica/microbiologia/ docTomaMuestras/1_Manual_recogida_transporte_ conservacion_muestras_microbiologia.pdf. Consultado: oct 2017.

14. Gobierno de Colombia, Alcaldía Mayor de Bogotá D.C., Secretaria Distrital de Salud, Dirección de Salud Pública. Manual para la toma de muestras para análisis microbiológico. Bogotá D.C., Colombia: Secretaría Distrital de Salud de Bogotá, D.C.; 2008.

15. Mühlhauser PM, Rivas JL. Laboratorio de microbiología: conocimientos básicos para un clínico. Revista Médica Clínica Las Condes 2014; 25: 569-579.

16. Baron EJ, Miller JM, Weinstein MP, Richter SS, Gilligan PH, Thomson RB, Jr., et al. A guide to utilization of the microbiology laboratory for diagnosis of infectious diseases: 2013 recommendations by the Infectious Diseases Society of America (IDSA) and the American Society for Microbiology (ASM)(a). Clin Infect Dis 2013; 57: e22-e121.

17. Kalenic S, Budimir A. The role of microbiology laboratory in healthcare-associated infection prevention. Int J Infect Control 2009; 5: i2.

18. Velasco J, Araque MdC, Araujo E, Longa A, Nieves B, Ramírez AC, et al. Manual práctico de microbiología clínica. Mérida, Venezuela: Publicaciones Vicerrectorado Académico, CODEPRE; 2008.

19. Caballería AL, Cabedo MC, Cardona CG, Granda DG, García PL, Coito JMN, et al. Garantía de calidad en los laboratorios de microbiología clínica. Manual de toma de muestras. Valencia, España: Generalitat Valenciana. Conselleria de Sanitat; 2004.

20. Canton R. Role of the microbiology laboratory in infectious disease surveillance, alert and response. Clin $\mathrm{Mi}-$ crobiol Infect 2005; 11 Suppl 1: 3-8.

21. Herrera ML, Campos M. Control de la Calidad para un Laboratorio de Microbiología. Rev Méd Hosp Nac Niños 2005; 40: 09-15.

22. Organización Mundial de la Salud (OMS), Oficina Regional para Asia Sudoriental. Quality Assurance in Bacteriology and Immunology. SEARO Regional Publication No. 47 (ed 3a). India: Organización Mundial de la Salud; 2012.

23. Cowie RA. Quality assurance for microbiology in feed analysis laboratories. In: Makkar HPS ed. FAO Animal
Production and Health Manual № 16. Roma: Food and Agriculture Organization (FAO); 2013.

24. Gobierno de Chile, Instituto de Salud Pública. Procedimiento control de calidad interno analitos cualitativos del área de bacteriología 2009. Disponible: http://www.ispch.cl/sites/default/files/PR\%20CCI\%20 Bacteriolog\%C3\%ADa.pdf. Consultado: oct 2017.

25. Winn WC, Allen SD, Janda WM, Koneman EW, Procop GW, Schrenckenberger PC, et al. Koneman Diagnóstico microbiológico. Texto y atlas color (ed 6a). Buenos Aires, Argentina: Editorial Médica Panamericana; 2008.

26. Morales-Parra GI. La coloración de Gram y su importancia en el diagnostico microbiológico. Rev Méd Electrónica Portales Medicoscom 2013; 8: 1-9.

27. Rand KH, Tillan M. Errors in interpretation of Gram stains from positive blood cultures. Am J Clin Pathol 2006; 126: 686-690.

28. Nagata K, Mino H, Yoshida S. [Usefulness and limit of Gram staining smear examination]. Rinsho Byori 2010; 58: 490-497.

29. Esparza GF, Motoa G, Robledo C, Villegas MV. Aspectos microbiológicos en el diagnóstico de infecciones del tracto urinario. Infectio 2015 ; 19 : 150-160.

30. Reyes-Hurtado A, Gómez-Ríos A, Rodríguez-Ortiz JA. Validez del parcial de Orina y el Gram en el diagnóstico de infección del tracto urinario en el embarazo: Hospital Simón Bolívar, Bogotá, Colombia, 2009-2010. Rev Colomb Obstet Ginecol [online] 2013; 64: 53-59.

31. Luján-Roca DA, Pajuelo-Camacho GR. Método rápido para detección de bacteriuria en examen microscópico de orina no centrifugada. Rev Biomed 2005; 16: 169-173.

32. Santos Fonseca RS, Casado Méndez PR, Méndez Jiménez $\mathrm{O}$, Martínez Méndez V, Jiménez Almaguer D, Cordoví Álvarez LC. Efectividad del sistema de puntuación de Nugent en el diagnóstico de vaginosis bacteriana. AMC 2017; 21: 729-739.

33. Mejía-Pérez D, Ángel-Müller E, Rodríguez-Hernández AE, Ruiz-Parra Al, Tolosa-Ardila JE, Gaitán-Duarte H. Características operativas del diagnóstico clínico con y sin pruebas de consultorio (ph y pruebas de aminas) para el diagnóstico de vaginosis bacteriana, en pacientes sintomáticas en Bogotá, Colombia. Rev Colomb Obstet Ginecol [online] 2015; 66: 253-262.

34. Figueroa-Damián R. Uretritis gonocócica. Perinatol Reprod Hum 2013; 27: 113-122.

35. Martínez MA. Diagnóstico microbiológico de las infecciones de transmisión sexual (ITS): Parte 1. ITS no virales. Rev Chil Infectol 2009; 26: 529-539.

36. Manavi K, Young H, Clutterbuck D. Sensitivity of microscopy for the rapid diagnosis of gonorrhoea in men and women and the role of gonorrhoea serovars. Int J STD AIDS 2003; 14: 390-394.

37. López-Jácome LE, Hernández-Durán $M$, Colín-Castro $C$, Ortega-Peña S, Cerón-González G, Franco-Cendejas R. Las tinciones básicas en el laboratorio de microbiología. Investigación en Discapacidad 2014; 3: 10-18.

38. Beveridge TJ. Mechanism of gram variability in select bacteria. J Bacteriol 1990; 172: 1609-1620.

39. Burguet-Lago N, Castillo-Abraham L. Control de calidad de los medios de cultivo utilizados en el monitoreo ambiental de las áreas clasificadas de producción. Rev Cubana Hig Epidemiol 2013; 51: 155-160. 
40. International Organization for Standardization (ISO). Microbiología de los alimentos para consumo humano y animal. Guía para la preparación y producción de medios de cultivo. Parte 1: Directrices generales para el aseguramiento de la calidad para la preparación de medios de cultivo en el laboratorio(ISO/TS 11133-1:2009). 2009. Disponible: http://www.en.aenor.es/DOCUMENTOS/ NORMALIZACION/NORMASNACIONALES/EXTRACTOS/ (EX)UNE-CEN_ISO(TS_11133-1=2009.pdf. Consultado: oct 2017.

41. Miranda C, López L, Caballeria AL, Marti AF. Recomendaciones sobre el aseguramiento de la calidad de medios de cultivo y reactivos. En: Grupo Colaborador GEGMIC, ed. Recomendaciones generales para el control de calidad interno en Microbiología Clínica. Madrid, España: SEIMC; 2004: 15-36.

42. March Rosselló GA, Bratos Pérez MÁ. Antibiograma rápido en Microbiología Clínica. Enferm Infecc Microbiol Clin 2016; 34: 61-68.

43. Araya-Díaz M, Prat-Miranda S, Ramírez-Muñoz V. Documentos técnicos para el laboratorio clínico. Recomendaciones para el control de calidad en Bacteriología: estudio de susceptibilidad antimicrobiana mediante difusión por disco: Gobierno de Chile, Ministerio de Salud, Instituto de Salud Pública de Chile, Departamento Laboratorio Biomédico Nacional y de Referencia; 2015.

44. Grupo para el Control de la Resistencia Bacteriana de Bogotá (GREBO). Manual de actualización en resistencia bacteriana y normas CLSI M100-S20. Bogotá D.C., Colombia: República de Colombia, Alcaldía Mayor de Bogotá, Secretaria Distrital de Salud; 2010.

45. Clinical and Laboratory Standards Institute (CLSI). Performance Standards for Antimicrobial Disk Susceptibility Testing. CLSI supplement M100 (ed 27a). Pensilvania, Estados Unidos: Clinical and Laboratory Standards Institute; 2017.

46. Rojo MD, Aguiar JM, Cercenado E, De Ory F, De La Rosa M. Recomendaciones para la implantación de la normativa de calidad UNE-ENISO 15189 en el laboratorio de microbiología clínica: bacteriología y serología. Enferm Infecc Microbiol Clin 2010; 28: 629-637.

47. Caballero E, Cooper Jd. Manual de control de calidad en microbiología. 2006. República de Panamá, Caja de Segu- ro Social, Dirección Nacional de los Laboratorios Clínicos, Laboratorio Clínico Complejo Hospitalario Metropolitano Dr. Arnulfo Arias Madrid. Disponible: http://studylib.es/ doc/3171892/manual-de-control-de-calidad-en-microbiologia-clinica. Consultado: oct 2017.

48. International Organization for Standardization (ISO). Laboratorios clínicos. Requisitos particulares para la calidad y la competencia (ISO 15189:2007). 2007. Disponible: https://www.isotools.org/2012/03/13/iso151892007-laboratorios-clinicos-requisitos-particulares-para-la-calidad-y-la-competencia/. Consultado: oct 2017.

49. International Organization for Standardization (ISO). Sistemas de Gestión de la Calidad. Fundamentos y vocabulario (ISO 9000:2005). 2005. Disponible: https://www. iso.org/obp/ui/\#!iso:std:iso:9000:ed-3:v1:es. Consultado: oct 2017.

50. Miranda C, Farga A, Lloret A, López L. Recomendaciones para el control de calidad interno en equipos de uso general en el laboratorio de microbiologia. En: Grupo Colaborador GEGMIC, ed. Recomendaciones generales para el control de calidad interno en Microbiología Clínica. Madrid, España: SEIMC; 2004: 45-54.

51. Gimeno C. Sistemas de gestión de la calidad en los laboratorios clínicos: certificación y acreditación. Enferm Infecc Microbiol Clin 2003; 21: 17-23.

52. Rehnuma B, Ibrahim M, Nasir TA. Quality Assurance and Quality Control in Clinical Laboratories. Pulse 2015; 8: 6265.

53. International Organization for Standardization (ISO). Requisitos generales para la competencia de los laboratorios de ensayo y de calibración (ISO/IEC 17025:2005). 2005. Disponible: https://www.iso.org/ obp/ui/\#iso:std:iso-iec:17025:ed-2:v1:es. Consultado: oct 2017.

54. República de Colombia, Instituto Nacional de Salud, Dirección Redes en Salud Pública, Subdirección Gestión de Calidad de LSP. Como implementar un programa de aseguramiento de calidad analítico. 2015. Disponible: http://www.saludcapital.gov.co/CTDLab/Publicaciones/2016/Como\%20implementar\%20\%20un\%20programa\%20de\%20aseguramiento\%20analitico.pdf. Consultado: oct 2017.

\begin{abstract}
The microbiology laboratory is a complex system, which involves many steps for each activity and different people, and where analytical results must be as accurate as possible. If the results are inaccurate, the consequences can be significant, including the performance of unnecessary procedures, delays in obtaining a proper result and implementation additional diagnostic tests that could be avoided. These consequences increase spending both economics terms as time and efforts of the staff. Most analytical techniques involve several procedures that are subject to some degree of imprecision and possibility of error. Therefore, it's important to apply an internal quality control that ensure that finished products or analytical values which are produced by a laboratory are sufficiently reliable and appropriate to the objective pursued. In this way, a microbiological laboratory must assess and document the performance of all aspects of its procedures that includes the quality of the sample, the efficiency of reagents and antisera, the staining, the culture media, the operation of instruments or equipment, the strains of reference, and the verification or validation of the results obtained. The aim of this manuscript is to present a literature review about some elements of microbiology laboratory that are susceptible of internal quality control, as an integral part of the daily work of the staff working in this one.
\end{abstract}

Key words: quality control, culture media, staining and labeling, reagents, equipment. 